\title{
illte
}

\section{On Behalf of}

THE COMMONWEALTH RELATIONS TRUST
Commonwealth Relations Trust Travelling Bursary: Call for Applications

Canadians working in educational media are fortunate this year in being able to apply for a bursary from the Commonwealth Relations Trus
which was established by a private donation in and a unity of ideals between the United Kingdom and other countries of the Commonwealth, through the extension of human contacts and ning in the spring of 1986 . Other bursars veginthe $U$. will be broadcasters, adult edustors, trade unionists, and librarians from several Commonwealth countries.

The Bursary will provide

a) one adult return fare, by the most direct and economical means, to the U.K.

b) allowances for local travel and other out-ofpocket expenses:

c) daily maintenance allowance on a generous scale for a period of three months from date of arrival

Candidates should:

a) offer assurances that they will not suffer financial loss as a result of taking up the award, but will continue to receive a salary:

b) be communicators in their profession and in a position to influence opinion in their field of endeavour

c) have a reasonable level of education in order and be able to act on their own initiative,

for a the 1930 s to promote a common understanding first-hand experience of current conditions. AMTEC has been asked to sponsor an annual award for educational broadcasters which pays to make the best use of their stay in the U.K. a) a short statement of the applicant's proposed objectives in applying for a bursary, what she or he hopes to obtain from the experience and what they feel they can contribute to the aims of the Trust;

the special area or areas of study to be

c) any known contacts in the U.K.

) previous travel abroad, including any visit to the U.K

e) address to which correspondence should be sent

aull curriculum vitae including education and work experience, with dates.

The award winner will be expected to prepare his or her own program, obpaining advice about in the U.K. by the end of April, 1986. A ten-page report must be submitted on conclusion of the

If you would like to apply for this award, please

Merrill Fearon

Chairman, AMTEC Committee for the

CRT Bursary

C/O The Provincial Educational Media Centre

Richmond, British Columbia V6X 188

Deadline for Applications:

Friday, May 23, 1986

\section{Applications should include:} forward the documentation described above to:

\section{BOOKS}

Greenfield, Patricia Marks. Mind and Media Effects of Television, Video Mass.: Harvard University Press, 1984. Reviewed by Patricia Dolan Lewis

Research based, yet written for the non-
cholarly reader, Mind and Media: The scholarly reader, Mind and Media: The and Computers is one dealing with media and the developing child. Puthor Patricia Marks Greenfield includes standard research on television, topic into the newer areas of video games and microcomputers. The continuin heme among the diverse media is their development. "Television and Social Reality", (chapter 4), one of the major effects issues today, is a short but up-to-date analysis of
current research. Sex-role stereotypes, representation of minority groups, consumer behavior and behavioral in fluences are all considered. The focus of he chapter, however, is on positive ef-
fects of television viewing and techniques to make television a positive experience. If Mind and Media has a weakness, it is this stated objective: to consider media
from a positive perspective. Studies trom a positive perspective. Studies
which show positive effects, critical viewing techniques which have positive results are emphasized in the research
presented. Although the reader may ecognize that these studies were selected support the author's fundamental
premise, one may underestimate the negative effects of the media. One may
also over-estimate the effects of literacy programs or critical viewing skills. or computer literacy, involves under-
standing the symbolic code of the medium. This point is illustrated very well in the chapter on visual skills an particular significance for the newer media. Children with more sophisticated viewing skills learn more when watching
television or film. Unlike print literacy

Patricia Dolan Lewis is adjunct instruc.

which children generally learn in skills, isual literacy is learned independently. deduce the symbolic code of the medium by watching programs. Obviously,
children are to learn efficiently and com prehensively from older as well as newe media, they should be taught basic sym-

medium. games is generally more speculative tha of television. For the computer illiterat read introduction to the subject. The addiional attraction of video games is considered, but the conclusions are a bi supericial. Based on small informal surveys of computer game players.
Greenfield concludes that time on the computer is time away from television. This she says is good because the comViolence in media is discussed, but the limited amount of research inhibits Educators will be particularly in lerested in the comments on word prosection on children using word processing provides some striking examples abo the usefulness of the technology in con-

Barcus, F. Earl. Images of Life on Praeger Publishers. 1983.

Reviewed by Patricia Dolan Lewis Based on the assumption that children of behavior from television, Barcus has presented the theoretical and procedural pramework for an extensive content ming The book also presents the results from an analysis of 50 hours of network grams geared to the child audience. Children's 'Televis of proves a framework and guidelines for further study. The results section focuses on CANADIAN JOURNAL OF EDUCATIONAL COMMUNICATION tor at Madonna College, Detroit the material on the much-researched field and independently owned station pro-

siders how the sexes are portrayed with espect as faplasis on recognition and portrayal of minority and ethnic group Finally, he reviews the portrayal of th family and kinship relationships on television. In addition to presenting the
results of the current study, the book in-

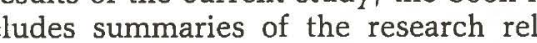
Many scholarly articles present the results of content analyses, however, few
of the articles explain the procedures usd to and explain the procedures us various categories. Reading this book will assist the researcher in developing and implementing a content analysis because the ps a confification procetures Content analysis is an obligatory procedure in evaluating the effects of tele sion on the child. It is obligatory because television is actually showing. Attempting to imply effects of television viewing whout first determining the program content analyses, however, is a long, expensive $p$ ter. Reading Images of Lif the initial planning necessary to implement content
television.

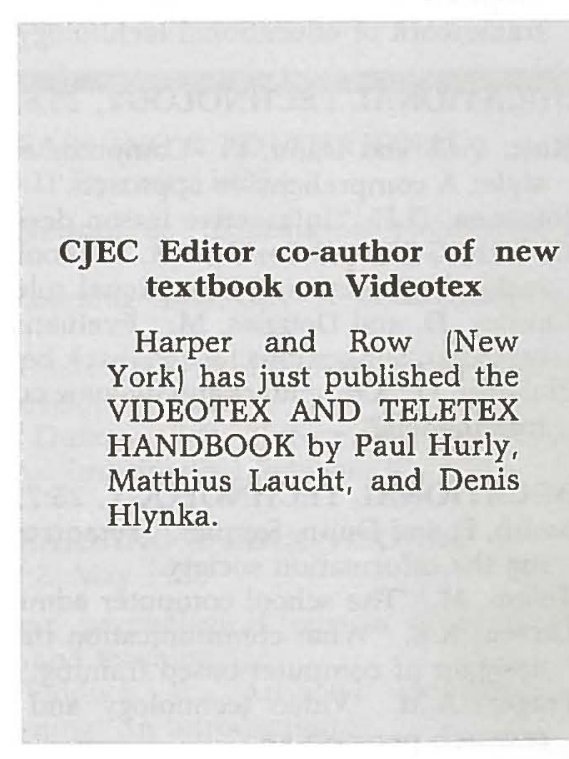

